\title{
Improving Direct Marketing Activities Effectiveness Using Analytical Models: RFM vs. Logit Model on a Casino Case
}

\author{
TJAŠA TABAJ PUŠNAR \\ Slovenia \\ tjasa.tabaj@gmail.com \\ DANIJEL BRATINA \\ University of Primorska, Slovenia \\ danijel.bratina@fm-kp.si
}

This research deals with the development and implementation of a large-scale analytics framework for improving segmentation and targeting of a service firm's direct marketing activities. The aim of the framework is to create a direct marketing response model using customers' demographics and other behavioural data (such as past response to direct marketing activities) from a casino (gambling industry). Prior to this research the company was using Recency-Frequency-Monetary (thereafter referred as RFM model). The statistical model used in our research, based on logit regression, significantly improves the accuracy of direct marketing activities as well as provides insight on relevant customers' characteristics that affect choice. We believe the results are a showcase of combining large, disaggregate, individual-level datasets with marketing analytics solutions for improving response to the marketing-communication mix. As per our knowledge in the time of writing this paper no such complete set of demographical and behavioural determinants have been used in direct marketing effectiveness analysis in the casino industry. Findings in this paper can be used by the company to considerably improve fine-tuning of target segments in their direct marketing activities, other industries (currently using RFM for direct marketing activities target group selection) can also benefit.

Key words: direct marketing effectiveness, RFM, logit modeling https://doi.org/10.26493/1854-4231.13.323-334

\section{Introduction and Theoretical Framework}

Direct marketing activities, when not correctly targeted, can have higher than necessary cost turning an otherwise profitable promotion activity into a loss. A variety of direct marketing optimization 
FIGURE 1

A Model of Customer Relationship Management

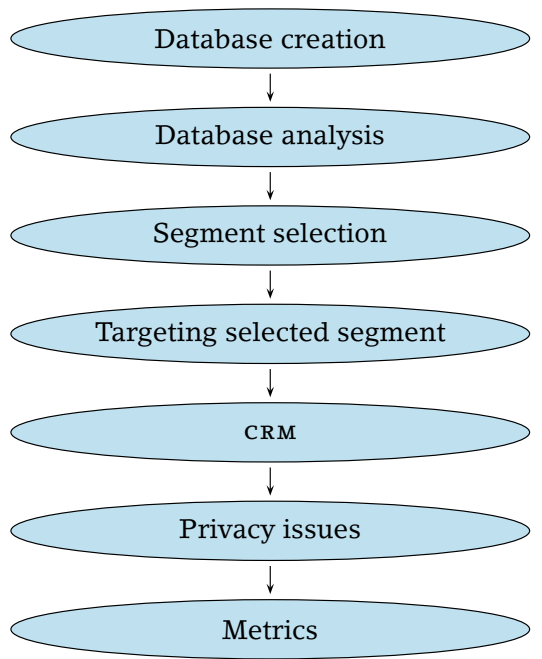

models have been developed in the past helping target profitable current and potential customers (Bult and Wansbeek 1995; Shepard 1999; Malthouse 2001). With recent greater emphasis on importance of customer relationship management from academia and practitioners and increased availability of large quantities of data (due to gains informatisation technology and associated statistical methods) the development of such tools has been accelerated producing a wide set of useful tools. A theoretical model of CRM has been introduced by Winer (2001) and is represented in figure 1.

Winer argues that ideal datasets should include customer's purchase history, sales person contact with the single customer, customer demographics and his responses to different marketing activities (Winer 2001, 92). The process of CRM can be monetarily expressed with Customer Lifetime Value (thereafter as CLV) which calculates the forecasted discounted net cash-flows a customer creates to the company and where the sum of all customers' Lvs is defined as Customer Equity (Wierenga 2008, 292). It is in this (long-term) perspective that a company should view its cost associated with acquiring new customers (and not through a single transaction). Most companies decide on running a CRM program based on the assumptions that a segment exists that is ready and willing to tighten its bonds with the company to establish a permanent relationship based on loyal purchases, that these customers are highly profitable and that a company can affect their loyalty through various approaches (Musek Lešnik 2008, 142). Such activities aim to increase consumers' 
loyalty, increased frequency and monetary value of transactions as well as creating positive attitudes towards the company and/or its brands (Sharp and Sharp 1997, 474). Several strategical and tactical activities follow the concept of CRM. One can find related topics in every CRM literature.

Critics of loyalty programmes argue that their high cost seldom create increased revenue, there is hardly any empirical evidence on increased consumption (and thus frequency). Wide spread of such activities dilutes their effectiveness, failure to convert non-users to users or increase loyalty within current customer base (Leenheer et al. 2007, 31).

Further increase of computing power and development of statistical tools have contributed to new (often real-time) data gathering called data mining, that involves searching for patterns in a large set of incomplete, unfiltered data. Data mining has more than once contributed to the development of unsought relationships resulting in breakthrough findings (Wang in Sing'oei 2013). Direct marketing analytics support has also benefited from data mining techniques (i.e. mass parallel processing or symmetric multi-processing; Churchill and Iacobucci 2002).

\section{Overview of Existing Models for Measuring Direct Marketing Effectiveness}

As mentioned earlier the most widely used model for optimal direct mail targeting is the RFM and its various modifications (Malthouse 2001). Bult and Wansbeek (1995) specify a profit function. By setting marginal costs equal to marginal revenues they determine which household should be receiving the offering. Improved RFM models namely AID (Automatic Interaction Detection) and $\mathrm{CH}^{-}$ AID (Chi Square AID) (Kass 1976) have been proposed to cope with limited variables selection used by RFM (only Recency, Frequency and Monetary) by adding demographics. All these early models have arbitrarily determined factors. In late 8oties regression models with statistical started to emerge (i.e. general customer purchase model; Bauer 1988). A popular model from Bansalben (Nash 1992) - gains chart analysis is based on a three-stage process. The initial stage analyses the test mailing response from target population by means of regression analysis to determine how household characteristics affect response by giving each household a probability that in future they will respond to marketing activities. The next step orders the population by the factors derived in the 1st stage. Last stage consists in dividing households with similar index value into groups of equal 
sizes and calculating the average response rate of the group. A cutoff point is arbitrarily determined and household above this point targeted.

Due to its ease of use, the RFM model is still being most widely used (Wollen 2017). Wheaton Group (see https://www.wheatongroup .com) argues that with increasing sizes of databases, RFM becomes inefficient and requires constant re-segmenting, especially in situations where a large heterogeneous group of products with different profitability are being offered. Our research shows how a casino (with a very large database of direct marketing events) can improve their targeting accuracy using multiple logit regression. A set of statistically relevant factors is also given (not possible with RFM). Profitability is not calculated in this paper but can easily be added to the model. With statistical tools available management can set-up a predictive tool in real time.

\section{Research Set-up and Dataset}

The objective of direct marketing models is to select a subset of the population that is going to receive a marketing communication with the aim of maximising client response and minimising cost. Thus, a direct marketing model must be able to predict the client response to the received offer based on the data that the company has gathered about the client (Taghva, Bamakan, and Toufani 2011). One of the most widely used segmentation methods for direct marketing support is the RFM analysis for clustering (Aggelis and Dimistris 2005). RFM is a classifying mechanism based on three sets of factors, namely time since last purchase, frequency of purchases and average value of purchase. Every customer is given a score upon which his participation in the next direct marketing campaign is based (Hosseini, Maleki, and Taghva 2010). RFM assumes that higher ranking customers are more responsive to direct marketing activities and that there is increased probability they would buy (Yeh, Yang, and Ting 2009) There are several versions of setting the three grouping factors levels. The most commonly used is a 5 levels/dimension, resulting in 125 segments (Olson and Chae 2012).

The expected contribution of a customer is $\mu_{i} \pi_{i}$, where $\mu_{i}$ represents the expected sales from customer $i$ and $\pi_{i}$ is the probability that the $i$ customer will respond to the communication.

A customer is profitable when $\mu_{i} \pi_{i}>c_{i}$, where $c_{i}$ is the projected cost for sending the message through to the customer $i$.

RFM has several flaws, mostly originating from its arbitrariness when selecting segment's criteria. It fails to predict the expected 

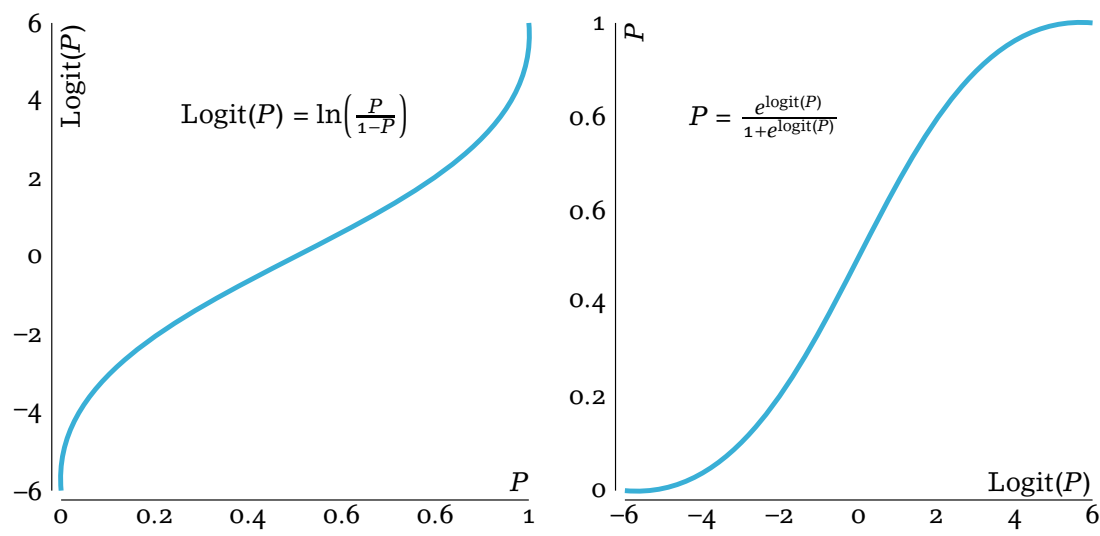

FIGURE 2 Logit Regression S-Shape Curve

number of buying customers in the future, it needs to be adjusted to specific industry needs and requires repeated trial-error fine tuning. To address some of the RFM disadvantages (mainly arbitrariness when selecting weights for the three criteria groups) we apply logistic regression on sample data from a service industry (gambling) and compare it with the current RFM model they are using to assess their direct marketing effectiveness.

Logit (or probit) regression analysis has been widely used in marketing research. Its main advantages are conceptual simplicity, it analytically defines weights (importance) for different criteria as opposed to RFM arbitrariness (Coussement, Harrigan, and Benoit 2015) and it is faster (Simonof 2016).

The logit model is a S-shaped success probability regression model with discrete dependent and various independent variables. It is modelled as:

$$
\ln \frac{p}{1-p}=\sum_{i=0}^{n} \beta_{1} X_{i},
$$

where $p$ represents the probability of success and $\sum_{i=0}^{n} \beta_{1} X_{i}$ the vector of independent variables. Solving for $p$ we get the $S$-shaped curve (see figure 2):

$$
p=\frac{e^{\beta_{0}+\beta_{1} x}}{1+e^{\beta_{0}+\beta_{1} x}} .
$$

The regression is solved by using OLM or GLM. Regression coefficients are tested using Wald statistics, which has a chi-square distribution: 
TABLE 1 Direct Marketing Activities

\begin{tabular}{|c|c|c|c|c|}
\hline \multirow[t]{2}{*}{ Month } & \multicolumn{2}{|r|}{2014} & \multicolumn{2}{|r|}{2015} \\
\hline & (1) & (2) & (1) & (2) \\
\hline January & 22 & sms, e-mail & 22 & sMs, e-mail \\
\hline February & 30 & mail & 28 & mail, sms in e-mail \\
\hline March & 28 & sms, e-mail & 23 & sms, e-mail \\
\hline April & & & 15 & sMs, e-mail \\
\hline May & 27 & sMs, e-mail & 29 & mail \\
\hline June & 29 & mail & 23 & mail, sms and e-mail \\
\hline July & 25 & mail, sms, e-mail & 28 & mail, sms, e-mail \\
\hline August & & & 29 & sms, e-mail \\
\hline September & 25 & sMs, e-mail & 34 & mail \\
\hline October & 28 & mail & 28 & sMs, e-mail \\
\hline Average & 26. & & 26. & \\
\hline
\end{tabular}

Nотеs Column headings are as follows: (1) response rate, (2) channel.

$$
\text { Wald }=\left(\frac{\beta_{i}}{S E \beta_{i}}\right)^{2}
$$

By adjusting the used parameters in the set of independent variables used in the regression we can fine-tune our model and compare it to the currently used RFM techniques.

\section{Data Set}

Our data consists of a collection of 2 years direct marketing communications to 18.000 clients and including their responses. In marketing, such a large database of responses is rather exceptional than common. In our case it has been made possible by a law requiring compulsory registration of the customers at casino entrance and tracking of their activities (game play) in the casino.

We use a combination of demographical and behavioural variables as the independent set of variables. Response rate was roughly $25 \%$. Table 1 shows types of communications per month and their response rates (there were no activities in November, December 2014 and September, December 2015).

The currently used RFM model classifies as potentially profitable (will probably engage in profitable activity for the casino after receiving the direct marketing communication) $25 \%$ of the customers base. Communication offers included a monetary value (to be spent in the casino), based on past expenditures and frequencies of visits. Some potentially profitable customers are filtered out due to incomplete data (missing address, phone number or e-mail). The 
тAвLE 2 Demographic Variables Descriptive Statistics

\begin{tabular}{llrr}
\hline Factor & & $N$ & $\%$ \\
\hline Gender & o Men & 10249 & 56.9 \\
& 1 Women & 7751 & 43.1 \\
\hline Nationality & 1 Slovenians & 741 & 4.2 \\
& 2 Italians & 14472 & 80.4 \\
& 3 Austrians & 2108 & 11.7 \\
& 4 Chinese & 566 & 3.1 \\
& 5 Other nationalities & 113 & 0.6 \\
\hline Distance & 1 Closer than 30o km & 14077 & 78.2 \\
& 2 3oo to 50o km & 1873 & 10.4 \\
& 3 More than $500 \mathrm{~km}$ & 2050 & 11.4 \\
\hline
\end{tabular}

company distinguishes 3 segments of customers based on recency (undisclosed criteria):

- Regular customers,

- Revitalisation segment (customers that hasn't visited for a short period of time), and

- Lost segment.

The first two segments are further split into (based on frequency):

- Low frequency segment and

- High frequency.

The resulting segments are further split into 21 segments based on average game bet they did in the past (detailed data has not been disclosed by the company).

RFM does not measure which segments has responded better to the communication sent, although this could be done post fest, the company does not do this kind of analysis. The logit model focuses on demographical and behavioural (only used in RFM) characteristics of customers namely: gender, age, nationality, distance from casino (demographical variables), monetary value of offer, type of service, average spending on games, bet size, number of visits, channel of communication and percentage of past responses to direct communications (behavioural variables). The dependent variable is whether the offer sent was used or not. Tables 2 and 3 show descriptive statistics for independent variables.

The success rate was $29.7 \%$. Beside conceptualizing the model, we have also tested some demographical/behavioural variables interdependency before constructing the logit model. 
TABLE 3 Behavioural Variables Descriptive Statistics

\begin{tabular}{lrrrr}
\hline Item & Average & SD & Min & Max \\
\hline Age & 54.80 & 15.50 & 18.00 & 98.00 \\
No. visits & 28.14 & 50.20 & 1.00 & 699.00 \\
Total bet & 109.00 & 404.00 & 0.60 & 28.15 \\
Average bet & 10.60 & 50.80 & 0.02 & 2314.00 \\
Incentive sent through marketing & 15.53 & 26.15 & 5.00 & 750.00 \\
Percentage of responses & 31.18 & 0.33 & & \\
\hline
\end{tabular}

NOTES $N=18000$.

Initial findings show that women (playing automates) play statistically different games than men (playing at tables), there is a statistically significant correlation between age and number of visits per week $(r=0.159$, sig. $=0.000)$ proving that elder people visit casinos more often. Not surprisingly, distance from casino affects the number of visits (group $1-0-300 \mathrm{~km}$ distance visited the casino 31 times in two years, group $2-300-500 \mathrm{~km} 17$ and group 3 - above $500 \mathrm{~km} 18.5$ times), although group 2 and 3 show adverse results. We attribute this to the fact that very distant high frequency/high monetary customers were transported free of charge to the casino. The average value played on machines was around 4 times smaller than at tables. While all nationalities show similar percentages of successful responses (from 30.4\% for Slovenians to 34.7\% for Austrians), Chinese exhibit only $12.1 \%$. For the casino it would be worth researching further why. Response rates were 31\% for e-mail and smss, while for classic mail they dropped to $15 \%$. The latter is also the costliest way of distributing communication.

\section{Results and Discussion}

Our model was constructed using 2 steps. In the initial step we included all the demographical variables we had available. The and model then only included statistically significant variables from the initial step. Nationality was recoded to (Italian/non-Italian) as this group represented $80 \%$ of the total sample. The initial model is shown in table 4.

Gender, nationality, game strength and past visits are not statistically significant. It is interesting that behavioural factors - number of visits and money spent do not affect direct marketing responses. This might suggest that there is a strong loyal customer base that ignores the incentives given by the casino.

This insight should be addressed by the casino when targeting customers to avoid giving incentives to those who would anyway be 
TABLE 4 First Model Regression Coefficients

\begin{tabular}{lrrrrr}
\hline Item & $B$ & SN & Wald & Sig. & Exp $(B)$ \\
\hline Age & -0.005 & 0.002 & 7.026 & 0.008 & 0.995 \\
Distance & -0.099 & 0.044 & 4.987 & 0.026 & 0.905 \\
Game type & 0.173 & 0.074 & 5.487 & 0.019 & 1.189 \\
Average bet & -0.002 & 0.001 & 10.190 & 0.001 & 0.998 \\
Incentive & 0.007 & 0.001 & 34.666 & 0.000 & 1.007 \\
Mail & 0.179 & 0.048 & 13.686 & 0.000 & 1.196 \\
Past response rate & 6.015 & 0.100 & 3589.036 & 0.000 & 409.691 \\
Gender & 0.053 & 0.049 & 1.132 & 0.287 & 1.054 \\
Nationality (Italian) & 0.086 & 0.063 & 1.906 & 0.167 & 1.090 \\
Game strength & 0.000 & 0.000 & 1.009 & 0.315 & 1.000 \\
No. of visits & 0.000 & 0.001 & 0.099 & 0.753 & 1.000 \\
Constant & -3.230 & 0.124 & 675.972 & 0.000 & 0.040 \\
\hline
\end{tabular}

TABLE 5 Regression Coefficients of the Final Logit Model

\begin{tabular}{lrrrrr}
\hline Item & $B$ & SN & Wald & Sig. & Exp $(B)$ \\
\hline Age & -0.004 & 0.002 & 5.756 & 0.016 & 0.996 \\
Distance & -0.092 & 0.044 & 4.373 & 0.037 & 0.912 \\
Game type & 0.189 & 0.071 & 7.130 & 0.008 & 1.208 \\
Average bet & -0.003 & 0.001 & 16.996 & 0.000 & 0.997 \\
Incentive & 0.006 & 0.001 & 37.115 & 0.000 & 1.006 \\
Channel & 0.176 & 0.048 & 13.426 & 0.000 & 1.193 \\
Past response rate & 6.022 & 0.090 & 4456.921 & 0.000 & 412.204 \\
Constant & -3.175 & 0.119 & 710.613 & 0.000 & 0.042 \\
\hline
\end{tabular}

coming to the service. The final model is thus shown in table 5 or in equation script of type:

$$
\operatorname{Logit}(p)=\beta_{\mathrm{o}}+\beta_{1} x_{1}+\beta_{2} x_{2}+\beta_{3} x_{3}+\cdots+\beta_{k} x_{k}=X \beta,
$$

as:

$$
\begin{aligned}
\operatorname{Logit}(p)= & -3.175+6.022 \times \text { past response rate }+0.176 \times \text { channel } \\
& +0.006 \times \text { incentive }-0.003 \times \text { average bet } \\
& +0.189 \times \text { game type },
\end{aligned}
$$

where $\operatorname{Logit}(p)=p /(1+p)$ and $p$ is the probability of successful communication or used coupon. We could also add distance and age to the final model that combined with these regression coefficients proved to be statistically significant but small (0.092 for distance and 0.004 for age). 
The major factor affecting future behaviour is Past response behaviour, followed by game type and Channel used. Based on this research one could simplify the model to only past response rate as other factors do not contribute much to the success of direct marketing campaign.

\section{Testing the Logit Model}

The model was tested with Omnibus test for validity and Cox \& Snells $R$-square as well as Nagelkerke $R$ to determine variance explained. Significance is o.ooo, which means that at the negligible risk we may reject the hypothesis, that the zero model is better than the last produced. We accept the hypothesis that the elaborated model is better. With the final model we can explain between 41.4 and $58.9 \%$ of the variance.

The model has correctly predicted $84.5 \%$ percent of responses. The model is more accurate for predictions of customers who won't use the offer. It correctly predicts $91.9 \%$ customers. But it's worse in predicting the announcements of customers who will use the offer, the percentage of correctly predicted is 66.9.

The equation that we got from modelling sample data can be applied to each customer in the database. We can calculate the probability of response, which is a combination of predictive variables: age, consumer distance from the casino, type of game, average bet, free play offer amount, direct marketing channel - mail and prior response to free play offer.

\section{Limitations and Further Research}

This research has been done using the available determinants as regressors, which is not the best practice. For a better insight of determinants affecting consumer behaviour, a qualitative research (focus groups, pilot research, more testing on smaller samples) as apriori would suggest a better set of determinants. The study is limited to a single casino and can thus be biased by specific properties of their customer base, meaning generalization is not straightforward. Due to data privacy RFM model couldn't have been analysed (i.e. determining which selection criteria would give the best results) and profitability evaluation has been made impossible.

Our research show how logit could be applied to decision making in direct marketing activities. The model we built for a casino company has a joint prediction probability of $84.5 \%$. In terms of industry research, a deeper analysis of performance between various types of RFM models and logit should be done, before the company switches 
to the use of the logit model. The company reports a big segment of lost customers (as per RFM model) which would require a broad understanding of their behaviour and a set of activities to bring them back. None of suggested models address this issue. Situational (those that only become loyal given a certain incentive from the company) and true loyalist should also be addressed separately, as company is losing money on the second group which would come to the service regardless of the direct marketing support received.

It also needs to be stressed that the model was built on a single casino customer base and it is yet to be tested on other casinos to eliminate specific casino properties.

\section{References}

Aggelis, V., and C. Dimistris. 2005. 'Customer Clustiering Using RFM Analysis.' http://www.wseas.us/e-library/conferences/2005athens/ cscc/papers/497-433.pdf

Bauer, C. L. 1988. 'A direct Mail Customer Purchase Model.' Journal of Direct Marketing, 2:16-24.

Bult, J. R., and T. Wansbeek. 1995. 'Optimal Selection for Direct Mail.' Marketing Science 14 (4): 378-94.

Churchill, G. A., and D. Iacobucci. 2002. Marketing Reserch: Methodological Foundations. Mason, он: South-Western Thomson Learning.

Coussement, K., P. Harrigan, and D. F. Benoit. 2015. 'Improving Direct Mail Targeting through Cutstomer Response Modeling.' Expert Systems With Application 42:8403-412.

Hosseini, S. M., A. G. Maleki, and M. R. Taghva. 2010. 'Cluster Analysis using Data Mining Approach to Develop CRM Methodology to asses the Customer Loyalty.' Expert Systems with Applications 37:5259-64.

Leenheer, J., H. J. van Heerde, T. H. A. Bijmolt, and A. Smidts. 2007. 'Do Loyalty Programs Really Enchance Behavioral Loyalty? An Empirical Analysis Accounting for Self-Selecting Menbers.' International Journal of Research in Marketing 24:31-47.

Kass. G. V. 1976. 'Significance Testing in Automatic Interaction Detection.' Doctoral dissertation, University of Intwatersand, South Africa.

Malthouse, E. 2001. 'Assessing the Performance of Direct Marketing Scoring Models.' Journal of Interactive Marketing 15 (1): 49-62.

Musek Lešnik, K. 2008. Od zadovoljstva potrošnikov do programov zvestobe. Koper: Fakulteta za management.

Nash, E. L. 1992. Predictive Modelling. New York: McGraw Hill.

Olson, D. L., and B. K. Chae. 2012. 'Direct Marketing Decision Suport through Predictive Customer Response Modeling.' Decision Support Systems 54:443-51. 
Sharp, B., and A. Sharp. 1997. 'Loyalty Programs and Their Imact on Repeat-Purchase Loyalty Patterns.' International Journal of Research in Marketing 14 (5): 473-86.

Shepard, D. 1999. The new Direct Marketing. New York: Irwin.

Simonof, J. S. 2016. 'Logistic Regression: Modeling the Probability of Success.' http://people.stern.nyu.edu/jsimonof/flasses/2301/pdf/ logistic.pdf

Taghva, M. R., M. H. S. Bamakan, and S. Toufani. 2011. 'A Data Mining Method for Service Marketing: A Case Study of Banking Industry.' Management Science Letters. 1:253-62.

Wang, J., and L. Sing' oei. 2013. 'Data Mining Framework for Direct Marketing: A Case Study of Bank Marketing.' ijcsi International Journal of Computer Science Issues. 10 (2): 198-203.

Wierenga, B. 2008. Handbook of Marketing Decision. New York: Springer.

Winer, Russel S. 2001. 'A Framework for Customer Relationship Management.' California Management Review 43 (4): 89-105.

Wollen, R. 2017. 'A Modern Approach to RFM Segmentation.' https:// cdn2.hubspot.net/hub/184373/file-41856256-pdf/docs/modern -approach-to-rfm-segmentation-ebook.pdf

Yeh, I-C., K.-J. Yang, and T.-M. Ting. 2009. 'Knowledge Discovery on RFM Model Using Bernoulli Sequence.' Expert Systems with Applications 36:5866-71.

This paper is published under the terms of the Attribution-

NonCommercial-NoDerivatives 4.o International (CC BY-NC-ND 4.0)

License (http://creativecommons.org/licenses/by-nc-nd/4.o/). 